\title{
Conexão eleitoral e reeleição entre deputados federais do sul do Brasil / 1998-2010
}

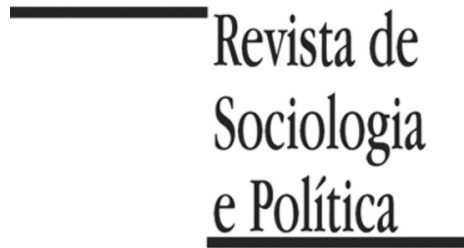

\author{
Ivann Carlos Lago e Edemar Rotta
}

\begin{abstract}
RESUMO
O artigo trata da conexão eleitoral entre deputados dos três estados do Sul do Brasil no período entre 1998 e 2010, abrangendo quatro eleições e três legislaturas. O objetivo principal do estudo foi identificar e analisar as associações entre o perfil de votação dos parlamentares e sua atuação no Congresso e entre esta e suas chances de reeleição na eleição subsequente. Para isso, utilizamos dois conjuntos de dados: a origem dos votos dos deputados federais dos estados do sul do Brasil entre as eleições de 1998 e 2010; e a atuação desses deputados, especialmente a partir das emendas individuais ao orçamento. Utilizando o modelo da "razão de chance", através do índice de Impacto Eleitoral das Emendas, demonstramos que a alocação de recursos através das emendas orçamentárias não é capaz de aumentar as chances de o deputado obter mais votos ente os eleitores dos municípios que as receberam. Concluímos que a transferência de emendas não pode ser tomada como estando entre as estratégias mais eficientes para assegurar a reeleição. Há que se rever, portanto, os modelos teóricos que tomam a transferência de recursos, especialmente através das emendas individuais ao orçamento, como estando entre as estratégias mais eficientes para assegurar a reeleição dos parlamentares brasileiros.
\end{abstract}

PALAVRAS-CHAVE: Conexão Eleitoral; Reeleição; Emendas Orçamentárias; Deputados Federais; Razão de Chance

Recebido em 22 de Novembro de 2012. Aprovado em 28 de Janeiro de 2013.

\section{Introdução ${ }^{1}$}

\footnotetext{
${ }^{1}$ Os autores agradecem os comentários e as sugestões dos pareceristas anônimos da Revista de Sociologia e Política.
}

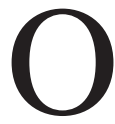
eixo deste trabalho é o desenvolvimento e utilização de um modelo estatístico capaz de medir, de forma simples, mas direta e detalhadamente, o impacto da distribuição de emendas individuais ao orçamento pelos deputados federais do Sul do Brasil a respeito de suas votações nas eleições seguintes, quando concorrem à reeleição. Trata-se da razão de chance, que mede a relação entre duas votações de um mesmo candidato, por município, dividindo-os entre os que receberam recursos de suas emendas e os que não receberam, identificando padrões distintos de variação entre as duas votações e permitindo estabelecer relações entre tal variação e a alocação de recursos. Não se trata, portanto, de buscar apenas a correlação entre alocar recurso de emendas e conseguir, ou não, reeleger-se; o que fazemos é identificar, com maior nível de precisão, se a alocação de emendas é capaz de aumentar a votação do deputado na eleição subsequente, exatamente naqueles municípios para os quais foram destinados os recursos das emendas de sua autoria.

Embora tanto na mídia como no mundo acadêmico não seja raro ouvirmos teses associando positivamente estratégias distributivistas de atuação no parlamento e chances de reprodução político-eleitoral, tal associação ainda está longe de ser devidamente demonstrada com pesquisas empíricas, visto que este permanece sendo um campo pouco explorado na Ciência Política brasileira. Como mostraram Pereira e Rennó (2001), são fartas as hipóteses e questões 
levantadas sobre o tema, mas muito raras as tentativas de testes empíricos a sustentá-las. Aliás, o próprio modelo utilizado por Pereira e Rennó (idem), por exemplo, identifica que liberação de emendas e reeleição possui associação significativa, mas não é capaz de demonstrar, efetivamente, que uma coisa é a causa da outra. A sofisticação da metodologia que analisa a relação entre emendas orçamentárias e reeleição, portanto, está entre as contribuições que pretendemos trazer com este estudo.

\section{Os estudos sobre reeleição}

Em vários aspectos, o pioneirismo dos estudos do impacto das estratégias de atuação parlamentar sobre as chances de reeleição dos parlamentares é atribuído à Mayhew (1974). Sua proposta parte dos referenciais da teoria econômica e de reflexões acerca das motivações humanas para então estabelecer hipóteses sobre os fundamentos do comportamento legislativo como uma variedade de comportamento humano. O objetivo da reeleição é tomado como princípio de destaque dentre essas motivações individuais. É a meta da reeleição que determina a natureza e as estratégias da relação que os congressistas estabelecem com os eleitores. É preciso sair das fronteiras do Congresso e tentar compreender como os congressistas relacionam-se com seus eleitores. A grande inovação de Mayhew (idem) está em adotar, a partir das teorias econômicas e de seu individualismo metodológico, o deputado como ator individual em suas análises, para além do modelo de explicação dos comportamentos dos parlamentares a partir do (suposto) controle exercido pelos partidos.

Tomando como objeto de estudos parlamentares estadunidenses, como atores políticos individuais, Mayhew (idem) apresenta três tipos bem delimitados de estratégias adotadas pelos congressistas, que exercem influência sobre suas chances de reeleição: (i) credit claiming: refere-se à propaganda que os deputados fazem, junto aos seus eleitores, de suas ações e conquistas no Congresso; (ii) pork barrel: diz respeito à distribuição de recursos e benefícios, que podem ser políticas públicas específicas ou mesmo ganhos sob a forma de favores a indivíduos ou grupos; (iii) position taking: mais próxima, entre as três, de uma variável mais ideológica, na medida em que se refere à tomada de posição diante de temas específicos.

Mayhew (idem) inaugura uma grande gama de estudos sobre reeleição. Muitos outros estudos importantes, como os de Arnold (1990), Jacobson (1990) e King, Keohane \& Verba (1994), por exemplo, embora adotando focos distintos e chegando a conclusões diferentes, são de algum modo tributários dos estudos daquele autor.

\section{II.1. Os estudos sobre reeleição no Brasil}

Apesar de a reeleição ser tema já bastante consolidado nos estudos de cientistas políticos em outros países, no Brasil, como apontam Pereira e Rennó (2001), são raras as análises que efetivamente realizam tentativas de teste para modelos explicativos sobre as determinantes das (re)eleições dos parlamentares. Segundo os autores, a maioria dos estudos "levanta" uma série de questões importantes sobre as estratégias eleitorais dos deputados, mas raramente testa possibilidades explicativas" (idem, p. 329). E as raras exceções que o fizeram ainda não testaram todas as variáveis dos modelos existentes. Eles ainda argu- 
mentam que, do modelo desenvolvido por Mayhew (1974), a variável que trata do credit claiming foi praticamente a única a orientar trabalhos importantes realizados por aqui. Sobre a relação entre gastos de campanha e reeleição também são quase inexistentes os estudos, com tendência de afirmar que as chances desta aumentam à medida que aumentam aqueles (Samuels 2000).

Ames (1995a; 1995b) trabalha com um modelo que toma as estratégias eleitorais dos deputados como ponto de partida para explicar os resultados das eleições. O autor argumenta que são eleitoralmente muito importantes as vantagens do candidato que tenha conseguido transferir recursos, especialmente do orçamento federal, cujo destino tenha beneficiado localidades ou distritos específicos. Consolidar a imagem de um deputado que "lutou pelos seus eleitores", pela sua região ou cidade, traz decisivos ganhos eleitorais, aumentando as chances de sucesso nas tentativas de reeleição. $\mathrm{O}$ distributivismo estaria a potencializar as chances de reeleição.

Mas o estudo de Ames teve seus resultados e argumentos contestados por Samuels (2000), outro brasilianista, para quem o fenômeno mais importante e que deveria, portanto, ser explicado, não é a reeleição (e suas determinantes), mas o contrário. As altas taxas de renovação da Câmara de Deputados é que constituiriam o grande fator a ser compreendido. Segundo o autor, um dos maiores contribuintes para essas altas taxas de renovação seria o desejo, predominante entre os parlamentares, de concorrer a cargos de maior expressão no executivo, resultado do desprestígio do parlamento. Samuels (idem) argumenta que os arranjos político-institucionais no Brasil não estimulam tanto a reeleição, e que as políticas distributivas, das quais lançam mão os deputados, exercem pouco impacto nas suas chances de sucesso em eleições futuras. Ao contrário, o fator de maior influência sobre as chances de reeleição seria o montante dos gastos de campanha e não o distributivismo do mandato do parlamentar. O que potencializaria as chances do deputado de voltar ao Congresso seria mais a quantia de dinheiro gasta diretamente com sua campanha do que o montante de recursos federais transferidos por sua influência (pork barrel).

Porém, esses estudos, embora significativos pelas contribuições que apresentam, pelas hipóteses que levantam e pelo debate que fomentam, ainda estão visivelmente orientados pela análise da conexão eleitoral que é característica dos Estados Unidos. No entanto, como apontam Pereira e Rennó (2001, p. 330), "algumas variáveis-chave, principalmente referentes ao papel legislativo do parlamentar e sua relação com o Executivo Federal, não são consideradas por esses autores. Além de deixar de lado variáveis importantes, seus modelos apresentam outros problemas, pois apenas trabalham com a tentativa do deputado de capitalizar a atenção ou de se promover em função de alguma realização (credit claiming), deixando de lado a distribuição efetiva dos benefícios particularizados representada pela execução das emendas, bem como a tomada de posição do parlamentar no exercício de suas atividades legislativas".

Em seu estudo Pereira e Rennó (idem) defendem que, dadas as características institucionais do sistema político brasileiro, os eleitores são levados a dar mais importância aos benefícios locais oriundos da atuação parlamentar do deputado do que a questões mais amplas do cenário político nacional e, neste sentido, o nosso sistema se pareceria bastante com o modelo estadunidense, de voto distrital. Isso leva os deputados a atuarem priorizando a transferência desagregada de benefícios governamentais, possíveis de serem geograficamente identificáveis e, portanto, recompensados pelos eleitores com votos nas eleições seguintes . Desse modo, o padrão de comportamento dos deputados brasi- 
leiros seguiria parâmetros parecidos com o dos seus pares estadunidenses, o que tornaria perfeitamente possível a utilização do modelo analítico de Mayhew para o estudo do caso brasileiro.

Pereira e Rennó (idem) tomam dois grupos de estratégias eleitorais diferenciadas para analisar o impacto de um conjunto de variáveis sobre as chances de reeleição de deputados brasileiros nas eleições congressuais de 1998: “[...] as orientadas a beneficiar os interesses de localidades específicas que os parlamentares avaliam como relevantes para seu futuro eleitoral, e aquelas direcionadas para a performance nacional com as quais o parlamentar também pretende viabilizar suas chances de sobrevivência política" (idem, p. 19).

Os autores concluem que a atuação do deputado no que diz respeito, por exemplo, à discussão de temas gerais e proposições legislativas, possui impacto reduzido nas chances de reeleição, importando muito mais a forma e a intensidade com que o deputado usa a estrutura do parlamento para transferir benefícios desagregados às suas bases eleitorais, visto que "[...] a distribuição de benefícios locais proporciona muito mais retornos eleitorais do que as atividades legislativas dentro da Câmara ou as posições de voto assumidas em relação a uma determinada política" (ibidem).

Pereira e Rennó (idem) argumentam ainda que, para aumentar as chances de reeleição, não basta que o deputado proponha transferência de benefícios para os municípios que compõem sua base eleitoral; é preciso assegurar que o Executivo execute as propostas e que o referido benefício realmente "chegue" ao município para que os eleitores recompensem o parlamentar com votos nas eleições seguintes.

Alguns anos mais tarde, Pereira e Rennó (2007) apresentaram um novo estudo, incluindo dados sobre as eleições de 2002, o que lhes permitiu uma análise em termos de tendência histórica e, consequentemente, um esboço de uma teoria da reeleição no Brasil. Os autores consideram novas variáveis e concluíram que "em 2002, padrão semelhante se repete com relação às variáveis locais: quem teve mais votos na eleição passada tem maiores chances de ser reeleito, assim como quem concentra menos seus votos em um único município. Também quem mudou mais de partido ficou prejudicado nas eleições em 2002. [...] As principais diferenças entre esses dois episódios eleitorais indicam que quem enfrentou menos competição em todo o estado em 2002 teve mais chance de ganhar as eleições, assim como quem teve mais projetos aprovados na câmara. Empresários também tiveram suas chances reduzidas em 2002 e o gasto de campanha teve seu impacto atenuado" (idem, p. 16).

Também descobriram que votar de acordo com as indicações da Presidência não exerce impacto direto nas chances de reeleição, mas contribui para aumentar a probabilidade de ter as emendas orçamentárias executadas, o que por sua vez possui impacto positivo sobre a reeleição. Ainda, tal correlação é mais acentuada naqueles pleitos onde o Presidente também concorre à reeleição - pois nesses casos a execução de emendas funciona como uma estratégia adicional para conseguir apoio político nos estados - diminuindo nos outros casos. Dessa forma, concluem que a conexão eleitoral no Brasil é fortemente condicionada pelo Executivo, mas este tem seu impacto variável de acordo com as características pelas quais exerce a Presidência. Presidentes que gozam de grande popularidade e que se envolvem diretamente no processo eleitoral exercem efeito positivo nas chances de reeleição dos deputados que os apoiam no Congresso. Quando isso não ocorre, outros elementos “[...] principalmente referentes à competitividade das eleições legislativas, passam a ser ainda mais 
influentes no sucesso eleitoral dos parlamentares candidatos à reeleição" (idem, p. 21).

Contudo, as descobertas desses autores têm limites. Seu maior problema é tomar a associação entre duas variáveis como indicador de que uma é, necessariamente, causa da outra. Eles demonstram que deputados que conseguem a liberação de mais emendas têm mais chances de reelegerem-se e concluem, então, que a liberação de emendas seja a principal causa da reeleição. Contudo, essa relação de causalidade não é clara. $\mathrm{O}$ deputado pode muito bem, por exemplo, conseguir a liberação de recursos para um município e reeleger-se com votação significativa em outro (o que é bastante comum). E a análise que os autores fazem não consegue captar isso. $\mathrm{O}$ fato de alguns deputados conseguirem liberar mais emendas pode indicar apenas que eles possuem maior poder de influência no Congresso e/ou junto ao governo, ou que ocupam posição de maior destaque e prestígio junto às lideranças do partido. E essas variáveis é que podem ter assegurado sua reeleição .

Mesquita (2008) também faz importantes apontamentos sobre o fenômeno da reeleição. Dentre eles, destaca-se a crítica que direciona às conclusões de Pereira e Rennó (2001), apontando para os limites de tal estudo a partir do recorte analítico que adota. Pereira e Rennó tomam, para analisar o impacto das emendas sobre as chances de reeleição, apenas as emendas destinadas pelos parlamentares aos municípios onde obtiveram maior votação. $E$ apenas investigam se há correlação entre destinar emendas a estes municípios e a incidência de reeleição. Não investigam, aponta a autora, nem se a reeleição foi conseguida por causa dessas emendas, nem se elas foram capazes de aumentar seus votos naqueles municípios mais do que nos outros que não receberam emendas, ou que as receberam mesmo não estando entre os que são de maior importância para o deputado. Ou seja, embora eles possam afirmar que deputados que destinam emendas para os municípios onde foram mais votados aumentam suas chances de reeleição, suas análises não permitem concluir, de forma categórica, que foi por causa de tais emendas que se reelegeram. Isso porque seu modelo de análise não permite identificar exatamente de onde vieram os votos que os reelegeram, nem se estes foram conseguidos por causa das emendas. A metodologia utilizada por Pereira e Rennó (idem), de acordo com Mesquita (2008, p. 26), "[...] não testa a relação entre emendas destinadas a um eleitorado e crescimento de votos entre este mesmo eleitorado. As unidades de agregação são distintas. Os votos que contam para a reeleição são obtidos em todo o estado, não se podendo descartar que a votação no município escolhido não tenha se alterado entre as eleições consideradas. Provavelmente, os resultados obtidos estão sendo determinados por fatores intervenientes".

Portanto, não se trata apenas de afirmar que existe relação entre destinar emendas para os municípios mais importantes para o deputado e reeleição. É preciso demonstrar em que medida tais emendas produzem efetivamente efeito eleitoral e se este é suficiente para afirmar-se que tal estratégia é capaz de assegurar a reeleição.

Mesquita (idem) também apresenta contribuição à análise da relação entre alocação de emendas e reeleição. Percebe que as taxas de reeleição são maiores entre os parlamentares de oposição, justamente os que apresentam menores índices de liberação de emendas, o que aponta para a necessidade de relativização das conclusões da tese distributivista para a qual as emendas são instrumento fundamental de reprodução eleitoral (Ames 2003). Mesquita conclui que os deputados "veem suas chances de se reeleger aumentadas frente aos 
demais os parlamentares que são titulares, que obtiveram maior proporção do quociente eleitoral no pleito anterior, que pertencem ao partido do governador eleito em seu estado e que são de partidos de oposição ao executivo federal. Trocar de legenda diminui as chances de sucesso na reeleição" (Mesquita 2008, p. 57).

A execução de emendas, segundo a autora, influenciaria as chances de reeleição, mas de maneira inversa ao comumente suposto: mais emendas liberadas estariam relacionadas à diminuição dos votos em relação à eleição anterior. Contudo, a análise também não deixa clara a relação de causalidade entre as duas variáveis. Afinal, a relação pode não ser simplesmente entre liberação de emendas e aumento/diminuição de votos em relação à eleição anterior. Temos de considerar aí uma questão estratégica importante: como se distribuem essas emendas? Seria preciso, então, verificar a relação entre o montante de emendas (valores) destinado a um dado município e o impacto que isso tem na proporção de votos que o deputado consegue nesse mesmo município na eleição seguinte. Se essa correlação for positiva, e mesmo assim o deputado não se elege, não significa que a emenda em si não seja importante, mas que o deputado "errou" na escolha de seu destino. É preciso, portanto, um modelo que seja capaz de medir, separadamente, o impacto das duas coisas. Ou seja, é preciso verificar o real impacto das emendas sobre o montante de votos do deputado no município que a recebeu, e entre as duas eleições. Se queremos medir o impacto das emendas sobre a votação do parlamentar, então a relação entre destinação de recursos e votação precisa ser verificada independentemente da reeleição. Nosso trabalho tem a intenção de contribuir a esse debate, buscando identificar e medir o impacto das emendas orçamentárias sobre as chances de reeleição a partir de um elemento específico: o aumento ou diminuição da votação do deputado, entre duas eleições consecutivas, nos municípios que foram beneficiados com a proposição, de autoria do mesmo deputado, de emendas orçamentárias, bem como sua respectiva liberação ou não.

\section{III. Índice de impacto eleitoral das emendas (IIEE)}

A hipótese distributivista, segundo a qual as emendas orçamentárias estão entre os principais recursos dos quais se utilizam os deputados para manter redutos eleitorais, é mais pressuposta do que comprovada. Ela tornou-se uma espécie de "lugar comum", embora ainda não tenha sido efetivamente comprovada em testes empíricos. Afinal, assumir que os deputados utilizam-se das emendas para transferir recursos para redutos eleitorais, e que o fazem tendo em vista a manutenção e ampliação das votações que ali possuem, não é o mesmo que afirmar que os eleitores estão "recompensando" tais representantes nas eleições seguintes, destinando-lhes seus votos. Mesmo os estudos de Pereira e Rennó (2001; 2007), ao concluírem que as emendas exercem impacto positivo sobre as chances de reeleição do parlamentar, não deixam clara a relação entre a transferência de recursos (das emendas) e os votos recebidos pelo deputado no município que a recebeu. O que eles demonstram é que deputados que distribuem recursos para seus redutos, por meio de emendas, aumentam suas chances de reeleição, mas seu trabalho não consegue identificar se são efetivamente os eleitores dos municípios beneficiados pelos recursos os responsáveis pela reeleição.

O que fizemos foi testar exatamente esse impacto das emendas - apresentadas e liberadas - sobre a proporção de votos recebida pelo deputado no município que a recebe entre duas eleições. Mais que analisar apenas a reeleição 
propriamente dita, buscamos verificar se a transferência de recursos para o município é capaz de manter ou mesmo de aumentar a proporção de votos que o deputado recebe de seus eleitores. Por isso, consideramos não apenas os deputados que conseguiram reeleger-se, mas também os que tentaram a reeleição sem sucesso. Afinal, nossa intenção foi medir a capacidade que as emendas possuem ou não de aumentar a votação do parlamentar nos municípios para os quais transfere recursos das emendas orçamentárias, "medindo" o impacto das emendas sobre a destinação de votos dos eleitores dos municípios que as recebem. A reeleição poderia ou não ter sido uma consequência desses votos. Pelo mesmo motivo, utilizamos o Índice de Impacto Eleitoral das Emendas (IIEE) e não índice de reeleição, pois o objetivo não é identificar a relação entre destinação de emendas e probabilidade de se reeleger, mas a correlação específica entre receber emendas e destinar votos ao seu autor nas eleições seguintes, do ponto de vista dos municípios para os quais foram destinadas.

Se analisássemos apenas a reeleição, correríamos o risco de deixar passar aspectos importantes. Por exemplo: um deputado pode privilegiar a transferência de recursos para os municípios que constituem sua base eleitoral (conexão eleitoral), o que pode ser identificado pelo Índice de Conexão (IC); ele pode também, na eleição seguinte, conseguir se reeleger. Mas se analisarmos apenas esses dois fatores separadamente, não teremos elementos suficientes para inferir que uma variável seja causa da outra. Ou seja, não temos como concluir que ele reelegeu-se porque transferiu recursos das emendas para aqueles municípios. Ele pode perfeitamente eleger-se com votação significativa em um conjunto de municípios, transferir recursos de emendas para esses mesmos municípios e, na eleição seguinte, reeleger-se com votação mais significativa em outros lugares. Alocação de recursos de emendas e reeleição podem, portanto, ser duas variáveis identificáveis em um dado grupo de deputados sem que, necessariamente, possuam entre si uma relação de causalidade.

Por isso, testamos não apenas o impacto da transferência de recursos (das emendas) e reeleição, mas verificamos também a relação entre alocação de recursos e manutenção, diminuição ou ampliação dos votos nos municípios específicos que receberam tais recursos. Para isso: (i) partimos dos dados das votações de cada deputado em cada município nas eleições em questão (eleição e reeleição); (ii) consideramos os recursos destinados a cada município por meio das emendas (propostas e liberadas) e (iii) aplicamos o modelo que mede a "razão de chance" entre a alocação de recursos e a destinação de votos ao deputado na eleição seguinte.

III.1. Sobre a "razão de chance"

A razão de chance, ou odds ratio, é a razão entre as chances de um dado evento ocorrer entre dois grupos distintos. Essa chance de ocorrência de um dado evento é obtida dividindo-se a probabilidade de ocorrência deste evento pela probabilidade de não ocorrência do mesmo evento entre dois grupos. Esses grupos podem ser, por exemplo, amostras de pessoas com ou sem uma determinada doença, quando se pretende medir a chance de a pessoa ter sido exposta a determinado agente ambiental, ou a chance de obter-se "cara" em relação a "coroa" no lançamento de uma moeda. Neste caso, a chance é de 1 $(=0,5 / 0,5)$. Já no lançamento de um dado, a chance de obter-se 6 em relação a outros pontos é de $(1 / 6) /(5 / 6)=1 / 5$, ou seja, tem-se 5 vezes mais chances de obter outro ponto diferente de 6 . Assim, as probabilidades que definem a chan- 
ce são estimadas por meio de uma amostra de observações. A estimativa de uma chance é uma razão entre proporções.

Comum em pesquisas nas ciências da saúde, a razão de chance pode ser utilizada para verificar as chances, por exemplo, de pessoas apresentarem câncer de pulmão tomando-se um grupo de fumantes e outro de não fumantes. Assim, se as chances de um evento em cada um dos grupos forem $\mathrm{p}$ (primeiro grupo) e q (segundo grupo), então a razão de chances pode ser calculada da seguinte forma:

$$
\frac{p /(1-p)}{q /(1-q)}
$$

$\mathrm{Ou}:$

$$
\frac{p /(1-q)}{q /(1-p)}
$$

Então: se a razão de chances for igual a 1, isso indica que a chance de o referido evento ocorrer é igual nos dois grupos; se superior a 1, indica que o evento tem maior chance de ocorrer no primeiro grupo; se menor que 1, indica que as chances de ocorrência do evento são menores no primeiro grupo do que no segundo.

Mas como esse modelo pode ser aplicado ao caso do estudo que desenvolvemos, que trata da relação entre destinação de emendas orçamentárias e conquista de votos? Ora, do ponto de vista do modelo e de seus fundamentos, a relação entre as duas variáveis pode ser analisada do mesmo modo, pois o que pretendemos é identificar a chance de um dado deputado ampliar sua votação em um dado conjunto de municípios para os quais destinou emendas, comparativamente a outro grupo para os quais não o fez. O que fizemos foi adaptar o modelo para a identificação da chance de o deputado aumentar sua votação, na eleição seguinte, entre os municípios para os quais destinou emendas e a chance de fazê-lo entre os municípios não contemplados. Trata-se de uma adaptação da idéia de odds ratio para o problema em questão, e não uma aplicação direta, pois não só identificamos a chance de o deputado ter conquistado votos em um município para o qual destinou emendas e outro para o qual não o fez, em uma mesma eleição, mas a razão entre o aumento ou diminuição de sua votação entre esses dois grupos de municípios.

Assim, se um determinado deputado aumentou sua votação em $10 \%$ entre os municípios que receberam recursos de suas emendas, e manteve a mesma votação entre aqueles que não receberam, então a razão de chance será maior que 1 (1,1 para ser exato); ou seja, destinar emendas para municípios aumenta a chance de expandir sua votação entre uma eleição e outra, comparativamente a não destinar emendas. $\mathrm{O}$ mesmo ocorrerá se ele tiver sua votação diminuída em $10 \%$ no primeiro grupo, mas a diminuição for de $20 \%$ no segundo; destinar emendas para municípios, neste caso, aumenta a chance de diminuir as perdas de votos entre uma eleição e outra (quaisquer sejam os motivos que façam com que um deputado perca votos entre uma eleição e a seguinte), comparativamente a não destinar emendas. A razão de chance é capaz de "captar" a relação entre o aumento ou diminuição da votação de um deputado no grupo de municípios que recebeu recursos e o aumento ou diminuição da sua votação no grupo que não recebeu. Dessa forma, avalia-se a chance de aumento dos votos entre os municípios que receberam ementas em relação aos que não receberam ementas. E essa chance é comparada com a chance na primeira eleição. Vejamos dois exemplos. 
No primeiro caso, temos:

Quadro 1 - distribuição hipotética de votos para deputado 1 - n

\begin{tabular}{lcc}
\hline & Eleição 2 & Eleição 1 \\
\hline Com emenda & 1200 & 500 \\
Sem emenda & 800 & 500 \\
Total & 2000 & 1000 \\
\hline
\end{tabular}

Ou:

Quadro 2- distribuição hipotética de votos para deputado 1 - \%

\begin{tabular}{lcc}
\hline & Eleição 2 & Eleição 1 \\
\hline Com emenda & 0,6 & 0,5 \\
Sem emenda & 0,4 & 0,5 \\
Total & 1 & 1 \\
\hline
\end{tabular}

Onde:

$p=(0,6)$ proporção de votos na Eleição 2 (E2) oriundos de municípios para os quais o deputado destinou emendas;

$1-p=(0,4)$ proporção de votos na E2 oriundos de municípios para os quais o deputado não destinou emendas;

$p /(1-p)=(1,5)$ chance de o deputado obter voto nos municípios para os quais destinou emendas, em relação aos municípios para os quais não destinou emendas, relativo à E2;

$q=(0,5)$ proporção de votos na Eleição 1 (E1) oriundos de municípios para os quais o deputado destinou emendas;

$1-q=(0,5)$ proporção de votos na E1 oriundos de municípios para os quais o deputado não destinou emendas;

$q /(1-q)=(1,0)$ chance de o deputado obter voto nos municípios para os quais destinou emendas, em relação aos municípios para os quais não destinou emenda, relativo à E1.

Então temos que a razão de chance, neste caso, é:

$$
\frac{p /(1-q)}{q /(1-p)}=\frac{0,6 /(0,4)}{0,5 /(0,5)}=\frac{1,5}{1}=1,5
$$

Assim, conclui-se que, no exemplo em questão, para a segunda eleição, a destinação de emendas aumenta a chance de o deputado conquistar votos em 1,5 vezes, em relação à primeira eleição. Isso indica que, para esse deputado, a destinação de emendas apresentou-se como estratégia positivamente associada à ampliação de sua votação entre as duas eleições consideradas. Tomemos agora um exemplo, também fictício, de um deputado cuja votação tenha aumentado menos nos municípios para os quais destinou emendas do que entre os demais.

Quadro 3 - distribuição hipotética de votos para deputado 2 - n

\begin{tabular}{lcc}
\hline & Eleição 2 & Eleição 1 \\
\hline Com emenda & 800 & 600 \\
Sem emenda & 1200 & 400 \\
Total & 2000 & 1000 \\
\hline
\end{tabular}

$\mathrm{Ou}:$ 
Quadro 4 - distribuição hipotética de votos para deputado 2 - \%

\begin{tabular}{lcc}
\hline & Eleição 2 & Eleição 1 \\
\hline Com emenda & 0,4 & 0,6 \\
Sem emenda & 0,6 & 0,4 \\
Total & 1 & 1 \\
\hline
\end{tabular}

Então, temos que a razão de chance é:

$$
\frac{0,4 /(0,6)}{0,6 /(0,4)}=\frac{0,67}{1,5}=0,45
$$

Como se vê, nesse exemplo temos que a destinação de emendas esteve associada à diminuição da proporção de votos conquistada pelo deputado. Embora sua votação tivesse aumentado, em números absolutos, nos dois grupos de municípios (com e sem emendas), o aumento entre o grupo que recebeu emendas foi, em termos proporcionais, menor do que o aumento no grupo que não as recebeu. Na segunda eleição, a destinação de emendas esteve associada à diminuição da chance de o referido deputado conquistar votos, em uma proporção de $1 /$ / 0,45. A chance deste deputado obter votos na E2 (em relação à E1) foi 2,25 vezes menor nos municípíos para os quais destinou emendas.

Assim, com o IIEE, independentemente de o deputado ter conseguido ou não se reeleger, podemos analisar o impacto específico das emendas sobre suas chances de obtenção de votos. Podemos verificar, empiricamente, se a alocação de recursos por meio de emendas possui efetivamente o poder de influência sobre a destinação de votos para o deputado na eleição subsequente.

III.2. Por período/ano de eleição

O IIEE médio para os três estados do Sul demonstrou que as emendas individuais ao orçamento não estão fortemente associadas à manutenção de redutos eleitorais. Ao contrário, para o conjunto dos deputados analisados a transferência de recursos das emendas esteve negativamente associada às votações do parlamentar entre duas eleições seguidas. Na média do grupo analisado, o crescimento da votação nos municípios que não receberam emendas foi maior do que naqueles que receberam, ou então que a diminuição nos municípios que não receberam emendas foi menor do que naqueles que as receberam.

De modo geral a destinação de emendas esteve associada ou a um aumento maior da votação nos municípios que não foram contemplados pelas emendas, ou então a uma diminuição menor nesses municípios em comparação àqueles que receberam emendas. De todo modo, o que os dados indicam é que as emendas orçamentárias não têm funcionado, ao menos nesse período e para os deputados desses três estados, como estratégia eficiente para ampliação de votos.

A Tabela 1 mostra ainda que não houve variações significativas no IIEE entre as três eleições. Não encontramos variações consideráveis no que se refere à relação entre destinação de recursos, das emendas, e votação do parlamentar na eleição seguinte. A destinação de recursos por meio de emendas não provocou, nos municípios que as receberam, destinação de votos ao deputado que a apresentou de forma mais acentuada do que nos municípios não contemplados pelos recursos. Por outro lado, quando se tomam os índices calculados para emendas efetivamente liberadas, diferenças mais significativas $(\mathrm{p}=$ 0,031) são encontradas. Embora ainda abaixo de 1, na média, o IIEE para o 
caso das emendas liberadas é consideravelmente maior do que aquele calculado apenas para as emendas apresentadas - 0,94 e 0,78, respectivamente. Isso indica que existe diferença entre propor emendas para os municípios e efetivamente assegurar sua liberação. A única exceção encontrada é para o caso do Rio Grande do Sul, estado para cujos deputados o IIEE médio para as emendas liberadas é de 1,05 , ou seja, ligeiramente superior a 1 , o que indica que a variação na votação dos deputados mostrou-se favorável naqueles municípios que efetivamente receberam recursos das emendas, em comparação com os que não receberam. Mas, mesmo no caso do Rio Grande do Sul, o IIEE é inferior a 1 quando se consideram apenas as emendas apresentadas. Por outro lado, quando consideramos as emendas liberadas, o menor IIEE encontrado é o dos deputados do Paraná, que fica em 0,83 .

A análise do Índice de Conexão (IC), que mede a relação entre a origem dos votos do deputado e o destino das emendas que ele propõe, mostrou como os parlamentares preocupam-se em "retribuir" os municípios que mais contribuem para sua eleição por meio da transferência de recursos (LAGO, 2010). Porém, os dados da tabela 1 sugerem que não há a mesma preocupação por parte dos eleitores em "retribuir" o deputado, autor das emendas, com novos votos na eleição seguinte. $\mathrm{O}$ alto IC médio para as emendas apresentadas demonstra que, em média, os deputados destinam aos municípios que mais lhe deram votos uma proporção de recursos - de suas emendas - maior que a proporção de votos que esses mesmos municípios lhe destinaram (Lago 2010). Porém, o IIEE, para emendas apresentadas, de 0,78 , indica que na eleição seguinte os municípios que receberam as emendas apresentam variação na proporção de votos destinada ao deputado em questão, que lhe é desfavorável em relação ao conjunto dos demais municípios. Ou seja, sua votação nos municípios aumentou menos, ou diminuiu mais do que aumentou, ou diminuiu (respectivamente) entre os municípios que não receberam emendas.

Precisamos relativizar, portanto, a hipótese segundo a qual o distributivismo, materializado na transferência de recursos das emendas orçamentárias, daria conta de explicar a "reprodução eleitoral" dos deputados. Se ele configura importante instrumento de "recompensa", por parte do deputado, aos seus redutos eleitorais, isso não é equivalente a um instrumento de reprodução da carreira política do parlamentar. Os deputados usam as emendas para retribuir a municípios e eleitores por seus votos. Mas os eleitores não usam seus votos para retribuir aos deputados pelas emendas que recebem.

Tabela 1 - índice de impacto eleitoral das emendas, por estado, segundo a eleição

\begin{tabular}{llcccc}
\hline & Eleição / Período & SC & PR & RS & Média \\
\hline $\mathbf{2 0 0 2}$ & Apresentadas & 0,76 & 0,79 & 0,85 & 0,81 \\
& Liberadas & 0,94 & 0,83 & 1,01 & 0,96 \\
$\mathbf{2 0 0 6}$ & Apresentadas & 0,69 & 0,74 & 0,82 & 0,76 \\
& Liberadas & 0,89 & 0,82 & 1,06 & 0,91 \\
$\mathbf{2 0 1 0}$ & Apresentadas & 0,70 & 0,73 & 0,84 & 0,77 \\
& Liberadas & 0,91 & 0,85 & 1,09 & 0,96 \\
\multirow{2}{*}{ MédiaGe- } & Apresentadas & 0,70 & 0,76 & 0,84 & 0,78 \\
ral & Liberadas & 0,92 & 0,83 & 1,05 & 0,94 \\
\hline
\end{tabular}

FonteS: Os autores, a partir dos dados dos Tribunais Regionais Eleitorais de cada estado e dados do Congresso Nacional. 
A Tabela 2, a seguir, apresenta o cruzamento do perfil de votação dos deputados com o Índice de Impacto Eleitoral das Emendas. A noção de conexão eleitoral é tomada aqui para analisarmos, desta vez, a relação entre a origem dos votos dos deputados em uma eleição e a associação entre transferência de recursos e alocação de votos, para o mesmo parlamentar, na eleição seguinte. Se o perfil de votação, como demonstramos (idem), influencia a forma como os deputados distribuem os recursos de suas emendas, possuindo forte associação com o IC, e se o IC está associado a diferentes IIEE (como será mostrado a seguir), então é de se esperar que o perfil de votação, mesmo que indiretamente, esteja associado a diferentes IIEEs.

De fato, existem variações significativas no IIEE entre os diferentes perfis de votação $(\mathrm{p}=0,008)$, tanto para as emendas apresentadas quanto para as liberadas. Porém, seguindo a tendência apontada acima, o IIEE é invariavelmente maior quando se consideram as emendas liberadas. Para ambos os casos, o maior IIEE é encontrado entre os deputados que possuem votação F/ND. Por outro lado, o menor IIEE está entre os deputados cuja votação é $\mathrm{C} / \mathrm{D}$, onde é de apenas 0,67 para as emendas apresentadas e de 0,84 para as liberadas.

Se votações mais fragmentadas estão associadas a maior IIEE, provavelmente é porque elas são um fator determinante de estratégias parlamentares menos associadas à retribuição dos votos recebidos com recursos de emendas. Deputados com votação fragmentada apresentam votações menos significativas em um ou em poucos municípios, o que os leva a priorizar com menor intensidade a retribuição desses votos com emendas orçamentárias durante seu mandato. Com isso, o IC de tais parlamentares é menor que o de seus pares que possuem votação concentrada, especialmente dominante. Como o IC está negativamente associado ao IIEE - este último é maior justamente entre os deputados com menor IC - isso gera o efeito identificado na Tabela 2, qual seja, o de forte associação entre dispersão dos votos e aumento do IIEE.

III.4. Variação do IIEE segundo o IC

Se o argumento de Baquero (1997) estiver correto e estiver mesmo ocorrendo um aumento da proporção daquilo que o autor chamou de "eleitor pragmático" - um eleitor que cada vez mais decide seu voto em função de

Tabela 2 - índice de impacto eleitoral das emendas, segundo o perfil de votação dos deputados

\begin{tabular}{llcccc}
\hline & Perfil de Votação & \multicolumn{3}{c}{ IIEE } \\
& & SC & PR & RS & Média \\
\hline Apresentada & C/D & 0,62 & 0,66 & 0,72 & 0,67 \\
& C/ND & 0,73 & 0,77 & 0,83 & 0,78 \\
& F/D & 0,64 & 0,74 & 0,82 & 0,76 \\
Liberada & F/ND & 0,93 & 0,94 & 0,99 & 0,95 \\
& C/D & 0,82 & 0,67 & 0,88 & 0,84 \\
& C/ND & 0,95 & 0,85 & 1,06 & 0,95 \\
Média Geral & F/D & 0,85 & 0,76 & 0,99 & 0,91 \\
& F/ND & 1,12 & 1,03 & 1,24 & 1,16 \\
& Apresentadas & 0,70 & 0,76 & 0,84 & 0,78 \\
& Liberadas & 0,92 & 0,83 & 1,05 & 0,94 \\
\hline
\end{tabular}

FonteS: Os autores, a partir dos dados dos Tribunais Regionais Eleitorais de cada estado e dados do Congresso Nacional. 
avaliações utilitaristas acerca das realizações concretas dos candidatos - então o próprio eleitorado estaria oferecendo incentivo ao distributivismo dos deputados. Se feitos como obras públicas e repasses de recursos financeiros (os quais podem transformar-se em obras) forem tomados como indicadores de boa atuação parlamentar, eles provavelmente estariam a ser recompensados pelo eleitor com votos nas eleições seguintes (e também indiretamente, pelo apoio dos líderes locais).

Do ponto de vista dos líderes políticos locais - especialmente prefeitos principalmente no caso de um deputado que efetivamente conseguiu a transferência de recursos e benefícios federais durante o seu mandato, faz sentido, ainda de acordo com a tese de Baquero (idem), pensar na reeleição deste como algo interessante. Seja como forma de recompensar o parlamentar pelos benefícios que já conseguiu para o município, seja como uma forma de assegurar a eleição de "alguém que já fez algo pela região", a reeleição de deputados que já conseguiram recursos seria, do ponto de vista utilitarista, algo relativamente previsível, como o interesse dos eleitores dos municípios "contemplados". Mas os dados que analisamos apontaram para uma tendência diversa. Vimos que o IIEE médio para os deputados dos três estados é menor que 1 , o que significa que o impacto da proposição e liberação de emendas para os municípios, em geral, é negativo para os deputados autores das emendas. Passamos agora a verificar a relação entre o Índice de Conexão (IC), e o impacto exercido pelas emendas sobre a votação do deputado nas eleições seguintes (IIEE).

Segundo o modelo distributivista, devemos supor que quanto maior for o IC (relação entre votos recebidos e recursos alocados) maior deveria ser o IIEE, dentro de uma lógica de raciocínio que seria a seguinte: o deputado elege-se com votação significativa em um determinado conjunto de municípios; esse deputado distribui recursos públicos, por meio das emendas orçamentárias, para os mesmos municípios, para recompensá-los por sua votação e na expectativa de mantê-la na eleição seguinte; em sua tentativa de reeleição, o deputado conta novamente com os votos desses municípios, visto que agora é hora de os eleitores "recompensarem" o parlamentar pelos benefícios recebidos, e "apostarem" na expectativa de que com mais um mandato ele continuará a transferir recursos para aquele município. Se esse modelo estiver correto, então os dados deveriam indicar uma associação forte entre IC e IIEE. Porém, os dados mostram exatamente o contrário.

De forma oposta à expectativa decorrente do argumento clássico segundo o qual as emendas orçamentárias são instrumento fundamental de manutenção de redutos eleitorais, os dados demonstram que quanto maior a coerência entre votos recebidos em uma eleição e os recursos transferidos pelo deputado durante a legislatura, menor a chance desse deputado ter, na disputa eleitoral seguinte, um aumento ou diminuição de votos nesses municípios (em relação à eleição anterior) maior do que o aumento ou diminuição junto aos municípios para os quais não destinou emendas.

Em geral, quanto maior o IC, menor é o IIEE. As emendas orçamentárias, portanto, não são ferramentas eficientes para a manutenção de redutos eleitorais. Antes, produzem efeito contrário: quanto mais o deputado preocupa-se em transferir recursos especificamente para os municípios onde obteve votação significativa na eleição anterior, menos a variação em sua votação na eleição seguinte lhe é favorável, quando se compara esse grupo de municípios com os outros que não receberam emendas. 
Como se mostra evidente na Tabela 3, a seguir, os únicos casos em que o IIEE médio é superior a 1 verificam-se quando se tomam os deputados com IC baixo e médio e consideram-se apenas as emendas liberadas. E, mesmo assim, o IIEE para o grupo de deputados com IC médio só é superior a 1 devido ao estado do Rio Grande do Sul, onde é de 1,30, pois ele é inferior nos estados de Santa Catarina $(0,99)$ e do Paraná $(0,89)$. De fato o IIEE só é superior a 1 , então, quando se tomam as emendas liberadas e os deputados com IC baixo para os três estados, e as emendas liberadas para os deputados com IC baixo e médio para o caso do Rio Grande do Sul.

No conjunto dos três estados, durante o período estudado, o aumento do IC esteve associado à diminuição do IIEE. Ao cruzarmos as duas variáveis, verificamos que o impacto da alocação de recursos por meio das emendas não é capaz de assegurar a reprodução eleitoral dos deputados, visto que o IIEE só é "positivo" para o deputado quando o IC é baixo. Ou seja, quanto maior a coerência entre a proporção de votos recebidos pelo deputado no município e a proporção de recursos a ele alocados, menor o impacto desses mesmos recursos sobre a conquista de votos na eleição seguinte. E, então, quanto menor aquela coerência, maior o impacto sobre a conquista de votos na eleição subsequente. Dessa forma, descobrimos que a alocação de recursos por meio de emendas individuais ao orçamento, embora classicamente tomada como indicador de distributivismo pelos estudos orientados pela noção de conexão eleitoral, e apesar de ser tomada como estratégia de "retribuição" dos deputados pelos votos recebidos, não se apresentou como ferramenta eficiente de manutenção e conquista de votos.

Com isso, demonstramos que as emendas orçamentárias não são instrumentos eficientes para manutenção de redutos eleitorais, nem para expansão daqueles redutos que já são importantes, eleitoralmente, aos deputados. Antes, elas funcionam de forma mais produtiva quando utilizadas para conquistar novos redutos, especialmente aqueles que até então não tinham importância eleitoral para o deputado. E, ainda assim, apenas quando o deputado consegue efetivamente a liberação dos recursos, não bastando a simples proposição da emenda.

Em resumo, então, podemos dizer, com base nos dados da Tabela 3, que as emendas orçamentárias podem ser instrumentos eficientes para a reprodução eleitoral do deputado, especialmente quando se trata de reeleição, desde que duas condições sejam satisfeitas: primeiro, essas emendas precisam ser desti-

Tabela 3 - índice de impacto eleitoral das emendas, por estado, segundo o ic médio dos deputados

\begin{tabular}{lccccc}
\hline & Índice de Conexão & \multicolumn{4}{c}{ IIEE } \\
& & SC & PR & RS & Média \\
\hline Apresentada & Baixo & 0,94 & 0,96 & 1,08 & 1,01 \\
& Médio & 0,82 & 0,83 & 0,88 & 0,85 \\
& Médio/Alto & 0,62 & 0,61 & 0,64 & 0,63 \\
\multirow{4}{*}{ Liberada } & Alto & 0,55 & 0,63 & 0,66 & 0,62 \\
& Baixo & 1,98 & 1,13 & 1,28 & 1,39 \\
& Médio & 0,99 & 0,89 & 1,30 & 1,13 \\
\multirow{4}{*}{ Média Geral } & Médio/Alto & 0,66 & 0,71 & 0,77 & 0,73 \\
& Alto & 0,61 & 0,58 & 0,71 & 0,67 \\
& Apresentadas & 0,70 & 0,76 & 0,84 & 0,78 \\
\hline & Liberadas & 0,92 & 0,83 & 1,05 & 0,94 \\
\hline
\end{tabular}

FonteS: Os autores, a partir dos dados dos Tribunais Regionais Eleitorais de cada estado e dados do Congresso Nacional. 
nadas a municípios que não estejam entre os que mais contribuíram, com votos, para a eleição do parlamentar no pleito anterior; segundo, é preciso que as emendas sejam efetivamente liberadas, não bastando apenas a sua proposição. Ou seja, o que percebemos com os dados acima apresentados é que as emendas individuais ao orçamento não são uma ferramenta eficiente para manter redutos eleitorais; mas podem ser importantes instrumentos para a conquista de novos redutos.

A hipótese, portanto, de que as emendas orçamentárias estão entre as principais estratégias do parlamentar para se reeleger (Pereira \& Rennó, 2001) precisa ser revista. Embora possa existir correlação positiva entre liberação de emendas e reeleição, o que descobrimos é que aquela não é, necessariamente, a causa desta. Se os deputados que conseguem maior índice de aprovação de suas emendas estão entre os que mais têm chances de reeleger-se, então precisamos encontrar outra variável ainda não identificada para apontar a causa da reeleição. $\mathrm{O}$ fato é que as emendas não são capazes de exercer impacto positivo sobre a votação dos deputados naqueles redutos onde ele já possuía votação significativa.

III.5. "Memória curta" do eleitor?

Em outra oportunidade (Lago 2010), demonstrou-se que o IC diminui à medida que o mandato do deputado avança. Existe uma tendência contínua, embora atenuada, de o parlamentar dar cada vez menos prioridade aos municípios que lhe são mais importantes e/ou dominados, a cada ano que passa de seu mandato. Aparentemente, os deputados utilizam-se da primeira metade de seu mandato para priorizar a recompensa aos municípios que lhe destinaram montantes significativos de votos; e passam, a partir do terceiro ano, a preocupar-se mais em utilizar as emendas para apostar na conquista de novos eleitores, em outros municípios. Os dados dos testes com o modelo do IIEE indicam que essa estratégia surte efeito positivo, já que destinar emendas para novos redutos resulta em maior impacto eleitoral nesses municípios do que destinar emendas para redutos antigos.

Independentemente do IC do deputado, o IIEE aumenta à medida que se passa a considerar os municípios que receberam emendas nos dois últimos anos do mandato. Do ponto de vista do deputado, entre utilizar a primeira fase do mandato para "pagar" os votos recebidos na eleição anterior e a segunda metade da legislatura para conquistar novos eleitores, a segunda iniciativa rende-lhe melhores resultados eleitorais na eleição seguinte. Portanto, do ponto de vista da maximização das chances de reeleição, é estrategicamente menos interessante para o deputado transferir recursos de emendas para os municípios que contribuíram significativamente para sua eleição anterior do que apostar na conquista de novos redutos eleitorais, especialmente nos dois últimos anos do mandato.

\section{Conclusões}

Em termos gerais, a partir do modelo de análise proposto e dos dados apresentados, podemos esboçar um modelo que associa a transferência de recursos das emendas e a reeleição, especialmente se três condições forem cumpridas: em primeiro lugar, é preciso que essas emendas sejam destinadas a municípios que não estejam entre os que mais contribuíram para a eleição do parlamentar 
Tabela 4 - índice de impacto eleitoral das emendas por período do mandato

\begin{tabular}{llccc}
\hline & Índice de Conexão & Anos 1 e 2 & Anos 3 e 4 & Média \\
\hline Apresentada & IC Baixo & 0,86 & 1,15 & 1,00 \\
& IC Médio & 0,72 & 0,99 & 0,85 \\
& IC Médio/Alto & 0,51 & 0,79 & 0,66 \\
\multirow{5}{*}{ Liberada } & IC Alto & 0,50 & 0,75 & 0,62 \\
& IC Baixo & 1,12 & 1,48 & 1,30 \\
& IC Médio & 0,94 & 1,25 & 1,10 \\
& IC Médio/Alto & 0,51 & 0,89 & 0,69 \\
\multirow{5}{*}{ Média Geral } & IC Alto & 0,44 & 0,77 & 0,62 \\
& Apresentadas & 0,68 & 0,90 & 0,78 \\
& Liberadas & 0,77 & 1,13 & 0,94 \\
\hline
\end{tabular}

FonteS: Os autores, a partir dos dados dos Tribunais Regionais Eleitorais de cada estado e dados do Congresso Nacional.

na eleição anterior; em segundo lugar, é preciso que as emendas sejam efetivamente liberadas, não bastando apenas a sua proposição; em terceiro lugar, o impacto das emendas nas chances de conquistar votos aumenta se os recursos forem transferidos nos últimos dois anos do mandato.

Demonstramos que Ames (2003), ao inferir que as emendas orçamentárias constituem instrumento por excelência de reprodução eleitoral, e Pereira \& Rennó $(2001 ; 2007)$, que afirmaram que a liberação de recursos das emendas está diretamente associada às chances de reeleição, não oferecem modelos capazes de compreender toda a complexidade da relação entre atuação parlamentar e captação de votos pelos deputados. Antes, parece que Figueiredo e Limongi têm razão quando afirmam que "[...] não se pode inferir a sorte eleitoral dos parlamentares apenas pela análise de suas emendas" (Figueiredo \& Limongi 2008, p. 12). A relação entre emendas orçamentárias e captação de votos é bem mais complexa, e nosso estudo, antes que solucionar a questão, apontou para a necessidade de reconhecer que as teorias até aqui formuladas precisam ser revistas.

Partimos da ideia de que o modelo de Pereira e Rennó (2001; 2007), para quem as emendas liberadas são a principal chave para compreender a reeleição dos deputados, embora apresente grandes contribuições, não dá conta de captar o real efeito das emendas orçamentárias sobre a captação de votos, necessários à reeleição. Se deputados que mais conseguem liberação de emendas também são os que mais se reelegem, isso não é suficiente para inferir que a liberação de emendas seja a causa da reeleição. De fato, como os dados aqui apresentados demonstraram, talvez precisemos de uma teoria que seja capaz de explicar por que os deputados que conseguem liberar mais emendas também são os mesmos deputados que mais conseguem se reeleger, possivelmente por outras razões ainda não identificadas. Possivelmente, fatores como a senioridade e a experiência junto ao Congresso e em suas relações com as estruturas do Executivo, bem como maior espaço nas estruturas partidárias, estejam a possibilitar maior apoio institucional aos deputados mais experientes, bem como maior projeção na mídia e maior prestígio junto às comissões parlamentares e ministérios. Com isso, talvez esses deputados estejam a conseguir, mais facilmente, que suas emendas sejam liberadas, ao passo que também conseguem consolidar sua imagem junto aos eleitores de seu estado, diversificando e ampliando suas bases eleitorais. Mas, nesse caso, a ampliação das bases eleitorais - aumentando as chances de reeleição - e a maior capacidade para liberar emendas orçamentárias seriam ambas causadas por outros fatores, ainda não satisfato- 
riamente analisados, e não possuiriam entre si uma relação de causalidade, como argumentaram os autores.

As emendas orçamentárias não são capazes de explicar a reeleição. Embora sejam utilizadas pelos deputados para "recompensar" seus eleitores, estes não as reconhecem como suficientes para retribuir ao seu autor com votos nas eleições seguinte. Então, mesmo que possam ser tomadas como indicadores de paroquialismo e de comportamentos distributivistas dos deputados, quando estes utilizam-na para recompensar municípios por votos recebidos, as emendas orçamentárias não podem ser tomadas como indicadores por excelência de que aquele distributivismo esteja na raiz da reprodução eleitoral dos parlamentares. Afinal, como demonstramos, o IIEE aumenta de forma inversamente proporcional ao IC. Ou seja, quanto mais o deputado preocupa-se em "retribuir", com recursos de suas emendas, aos municípios que mais lhe deram votos, menos as emendas têm impacto positivo sobre suas chances de conquistar eleitores nesses mesmos municípios na eleição seguinte, em comparação às suas chances de conquistar votos nos municípios que não receberam emendas. Emendas orçamentárias só estão positivamente associadas ao aumento das chances de obtenção de votos (IIEE maior que 1) se forem efetivamente liberadas e se forem destinadas para municípios que não estejam entre os que mais contribuíram para a eleição do deputado no pleito anterior. E ainda assim a associação não é forte o bastante para permitir que tomemos as emendas orçamentárias como a principal causa da reeleição.

Ivann Carlos Lago (ivann@uffs.edu.br) é Doutor em Sociologia Política pela Universidade Federal de Santa Catarina (UFSC) e Professor da Universidade Federal da Fronteira Sul (UFFS).

Edemar Rotta (erotta@uffs.edu.br) é Doutor em Serviço Social pela Pontifícia Universidade Católica do Rio Grande do Sul (PUC-RS) e Professor da Universidade Federal da Fronteira Sul (UFFS).

\section{Referências}

Ames, J.B., 2003. Os entraves da democracia no Brasil. Rio de Janeiro: FGV.

1995a. Electoral Rules, Constituency Pressures, and Pork Barrel: Bases of Voting in the Brazilian Congress. The Journal of Politics, 57(2), pp. 324-343.

1995b. Electoral Strategy under Open-list Proportional Representation. American Journal of Political Science, 39(2), pp. 406-433.

Arnold, R.D., 1990. The Logic of Congressional Action. New Haven: Yale University.

Baquero, M., 1997. Novos padrões de comportamento eleitoral: pragmatismo nas eleições municipais de 1996 em Porto Alegre. In: . ed. A lógica do processo eleitoral em tempos modernos. Porto Alegre: UFRGS.

Carvalho, N.R., 2003. E no início eram as bases: geografia política do voto e comportamento legislativo no Brasil. Rio de Janeiro: Revan.

Figueiredo, A.C. \& Limongi, F.P., 2008. Política orçamentária no Presidencialismo de Coalizão. Rio de Janeiro: FGV.

Jacobson, G., 1990. The Effects of Campaign Spending in House Elections: New evidence for old arguments. American Journal of Political Science, 31(1), pp. 126-141.

King, G., Keohane, R.O. \& Verba, S., 1994. Designing Social Inquiry: Scientific inference in qualitative research. Princeton: Princeton University.

Lago, I.C., 2010. Conexão eleitoral: geografia do voto, comportamento parlamentar e reeleição entre os deputados federais do sul do Brasil / 1998-2006. Florianópolis. Tese de Doutorado. Universidade Federal de Santa Catarina.

Mayhew, D.R., 1974. Congress: The electoral connection. New Haven: Yale University.

Mesquita, L., 2008. Emendas ao orçamento e conexão eleitoral na Câmara dos Deputados Brasileira. Dissertação de Mestrado. São Paulo: Universidade de São Paulo.

Pereira, C. \& Rennó, L., 2001. O que é que o reeleito tem? Dinâmicas Político-Institucionais Locais e Nacionais nas Eleições de 1998 para a Câmara dos Deputados. Dados, 44(2), pp. 323-362.

2007. O que é que o reeleito tem? O retorno: o esboço de uma teoria da reeleição no Brasil. Revista de Economia Política, 27(4), pp. 664-683. 
Samuels, D., 2000. The Gubernatorial Coattails Effect: Federalism and congressional elections in Brazil. The Journal of Politics, 62(1), pp. 240-253.

Saugo, J.F. 2007. Geografia do voto e conexão eleitoral no Rio Grande do Sul: 1994-2006. Dissertação de Mestrado. Porto Alegre: Universidade Federal do Rio Grande do Sul.

\section{ABSTRACT}

The article deals with the electoral connection between members of the three southern states of Brazil between 1998 and 2010 , covering four elections and three legislatures. The main objective of the study was to identify and analyze the associations between the profile of the parliamentary vote and his performance in Congress and between this and their chances for reelection in the subsequent election. Therefore, we use two data sets: the origin of the votes of deputies from the southern states of Brazil between 1998 and 2010 elections, and the action of these MPs, especially from the individual budget amendments. Using the model of the "reason of chance", through the index of the Electoral Impact of Amendments, we demonstrated that the allocation of resources through the budget amendments are not able to increase the chances of the deputy of obtaining more votes between the electors of the cities that received them. We concluded that the transfer of amendments cannot be taken as being among the most effective strategies to ensure reelection. Therefore, the theoretical models that take the transfer of resources must be reviewed, especially through the individual budget amendments, as being among the most effective strategies to ensure the reelection of Brazilian congressmen.

KEYWORDS: Election Connectiong; Reelection; Budget Amendments; Federal Deputies; Reason of Chance 